\title{
Entry of technetium-99 into the human food chain through the use of seaweed as soil conditioner
}

\author{
S. Webster and C. Salt \\ Department of Environmental Science, University of Stirling, Stining FK9 4LA, U.K.
}

\begin{abstract}
The accumulation of ${ }^{\% \mathrm{Tc}}$ by $F$ ucus vesiculosus and its subsequent use as a soil conditioner in coastal areas gives rise to a potential pathway for the transfer of ${ }^{99} \mathrm{Tc}$ to terrestrial ecosystem and on to bumans. Preliminary results from a small-scale study of the release of ${ }^{9 \%} \mathrm{Tc}$ from Fucus vesiculosus into a sandy, coastal soil suggest that around $20 \%$ of the ${ }^{99} \mathrm{Tc}$ present in the seaweed is teleased within 17 days (2.7 weeks) of its addition to the soil, even though the decomposition rate, measured by the $\mathrm{CO}_{2}$ production of soil microorganisms, remained low over that period. Further analyses will be carried out to determine the rate of ${ }^{90} \mathrm{Tc}$ release in the larter part of the experiment when the decomposition rate had increased.
\end{abstract}

\section{INTRODUCTION}

\subsection{Background}

The commissioning of the Enhanced Actinide Removal Plant (EARP) by BNFL at Sellafield, UK in 1994 to treat stored waste has led to an increase in the concentration of technetium $99\left({ }^{94} \mathrm{Tc}\right)$ in the Irish Sea [1]. As ${ }^{99} \mathrm{Tc}$ is a long-lived artificial radionuclide with a half-life of 213000 years it has the potential to contaminate the environment for a very long time. It has been shown that ${ }^{99} \mathrm{Tc}$ is bioaccumulated by brown seaweed, particularly Fucus species and Ascophyllum nodosum, with concentration factors for Fucus species in excess of $1 \times 10^{5}$ (wet weight) [2]. The accumulation of ${ }^{99} \mathrm{Tc}$ by brown seaweed gives rise to a potential pathway for the transfer of ${ }^{99} \mathrm{Te}$ to terrestrial ecosystems and on to humans, through the use of seaweed as an agricultural soil conditioner in coastal areas [3]. This practice, while not as widespread as in the past, still occurs on a small scale on the west coast of Britain, where in some instances the seaweed is collected from the shore close to the reprocessing plant at Sellafield. Several studies have shown that ${ }^{99} \mathrm{Tc}$ (in the soluble pertechnetate ion form) is readily taken up from the soil by certain plant species [4-7].

\subsection{Research Programme}

This paper presents the preliminary results of the initial experiment of a NERC CASE studentship with $\mathrm{CEH}$ Merlewood that began in October 2000. The aim of the research programme is to study the bioavailbility of ${ }^{99} \mathrm{Tc}$ present in the brown seaweed, Fucus vesiculosus, to plants. The natural system under investigation is very complex but Figure 1 shows a simplified version. 


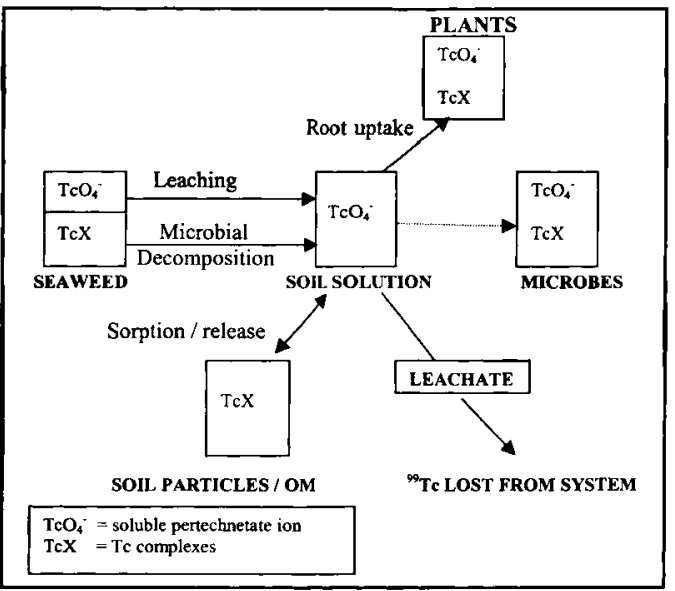

Figure 1: Simplified diagram showing system under investigation

In particular this programme aims to identify the mechanisms involved in the release of ${ }^{99} \mathrm{Tc}$ from Fucus vesiculosus into the soil matrix and soil solution, to monitor the uptake of ${ }^{99} \mathrm{Tc}$ from the soil solution by spinach plants and to estimate the loss from the soil through leaching.

\section{INITIAL EXPERIMENT}

The aim of this small-scale experiment was to monitor the rate at which ${ }^{59} \mathrm{Tc}$ present in Fucus vesiculosus is released into the soil.

\subsection{Method}

A series of 1 litre pots (Figure 2) were set up containing $50 \mathrm{~g}$ (wet weight) Fucus vesiculosus (collected from the shore adjacent to the reprocessing plant at Sellafield) chopped into $4-6 \mathrm{~cm}$ pieces, mixed evenly with $250 \mathrm{~g}$ (field moist) ${ }^{99}$ Tc-free sandy, coastal soil from the east coast of Scotland. At the time of setting up, a sample of the seaweed added to each pot was retained for ${ }^{99} \mathrm{Tc}$ analysis. In this way the amount of ${ }_{9}^{9} \mathrm{Tc}$ added to each pot could be determined. Twenty-one test pots and 21 controls (soil only) were set up, kept at ambient temperature and maintained at $65 \%$ field capacity. 


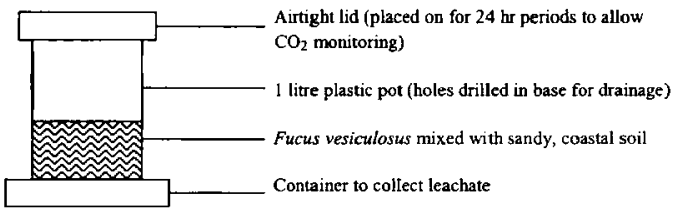

Figure 2: Experimental pots

The experiment ran for 20 weeks from the beginning of February to mid June 2001. At intervals 3 test and 3 control pots were removed from the experiment for sampling. At each of the 7 sampling dates the rate of decomposition was monitored by measuring the $\mathrm{CO}_{2}$ production by soil microorganisms over a 24 hour period. This was done by capping the pots, then immediately taking air samples (base measurements), then taking further samples 24 hours later. The samples were then analysed using gas chromatography. The seaweed was removed manually from the test pots, dried at $60^{\circ} \mathrm{C}$ and retained for future ${ }^{99} \mathrm{Tc}$ analysis. The remaining soil was also dried at $60^{\circ} \mathrm{C}$, ground then analysed for ${ }^{99} \mathrm{Tc}$ using the method devised by Wigley et al. [8].

\subsection{Results}

\subsection{1 $\mathrm{CO}_{2}$ production}

The difference in $\mathrm{CO}_{2}$ concentration between the base and 24-hour samples of air from the sealed pots was taken as representing the amount of $\mathrm{CO}_{2}$ produced by the soil microorganisms during decomposition of the seaweed. The $\mathrm{CO}_{2}$ produced by the soil microorganisms was calculated as the number of moles of $\mathrm{CO}_{2}$ per gram of soil (dry weight) produced in the 24 -hour period. The results (mean values, $\mathrm{n}=3$ ) obtained from the 7 sampling dates were plotted to show the change in decomposition rate over time (Figure 3)

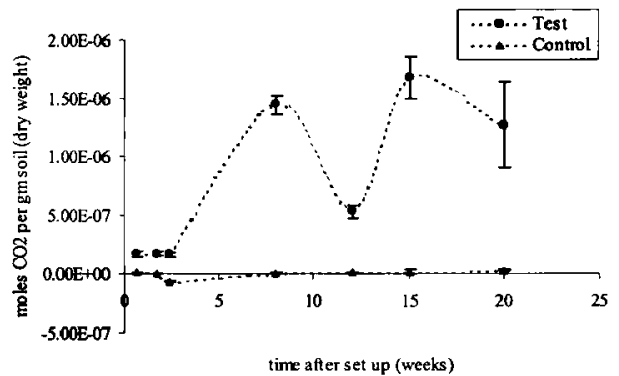

Figure 3: Change in $\mathrm{CO}_{2}$ production rate over time (beginning of February to mid June 2001)

The results obtained show that for the first 17 days (2.7 weeks) of the experiment the $\mathrm{CO}_{2}$ levels in the test pots remained low and there was very little difference in $\mathrm{CO}_{2}$ production between the test and 
control pots. On the fourth sampling date (8 weeks after set up), the rate of $\mathrm{CO}_{2}$ production in the test pots had risen markedly after which it fell before rising again at the sampling point 15 weeks after set up. On the final sampling date ( 20 weeks after set up) the rate had fallen again slightly. The rate of $\mathrm{CO}_{2}$ production in the control pots remained fairly constant throughout the experiment.

\subsection{2 $99 \mathrm{Tc}$ analysis of seaweed and soil samples}

The analyses of the soil and seaweed samples are still in the early stages. Initial results show that samples $(n=3)$ of the seaweed (taken when pots set up) have a mean ${ }^{99} \mathrm{Tc}$ content (wet weight) of $8005 \mathrm{~Bq} \mathrm{~kg}$. Preliminary results from analyses of soil samples show that ${ }^{99} \mathrm{Tc}$ is released from the seaweed into the soil. Results suggest that approximately $20 \%$ (mean value, $n=3$ ) of the initial ${ }^{99} \mathrm{Tc}$ added to the pot was released into the soil 17 days ( 2.7 weeks) after the seaweed had been added to the soil (Figure 4$)$.

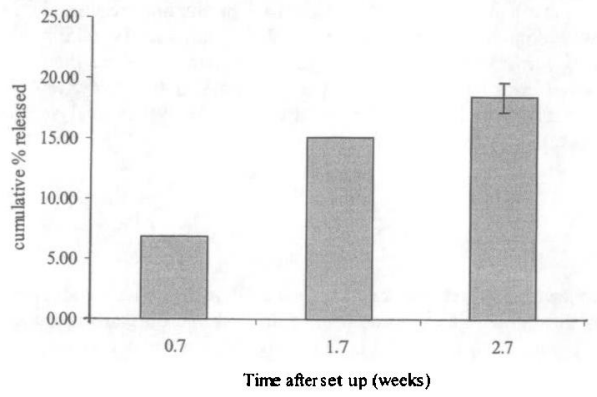

Figure 4: Cumulative percentage release of Tc from Fucus vesiculosus over time

\section{DISCUSSION}

The low $\mathrm{CO}_{2}$ production in the test pots in the first 17 days ( 2.7 weeks) indicates that the decomposition rate during that period was low. The low production rate is likely to be due to the low ambient temperature (mean monthly temperature over that period $3.6^{\circ} \mathrm{C}$ ), The effective minimum temperature for activity for the majority of soil microorganisms is between $5-10^{\circ} \mathrm{C}$ [9]. The rise in production at 8 weeks after set-up does not seem to be the result of a rise in ambient temperature (mean monthly temperature over that period $4.2^{\circ} \mathrm{C}$ ). The rise in microbial activity may be in response to the presence of easily broken down organic material within the seaweed, with the subsequent fail in $\mathrm{CO}_{2}$ production signalling the exhaustion of this readily decomposable material. The rise in $\mathrm{CO}_{2}$ production at 15 weeks after set up may indicate the beginning of the breakdown of more resistant organic material in the seaweed or may in part be due to a rise in ambient temperature (mean monthly ambient temperature now $12{ }^{\circ} \mathrm{C}$ ).

The release of approximately $20 \%$ of the ${ }^{99} \mathrm{Tc}$ added to the pots, by 17 days after set-up while the decomposition rate remained low, suggests that a considerable amount of ${ }^{99} \mathrm{Tc}$ can be released from the seaweed before large-scale decomposition of the plant material occurs. This may be due to leaching of ${ }^{99}$ Tc present as the soluble pertechnetate ion in the seaweed. A possible error may have resulted in an overestimation of the amount of ${ }^{\$ 9} \mathrm{Tc}$ released over this period. The manual removal of seaweed from the pots may have resulted in some small fragments of seaweed remaining in the soil thus increasing the ${ }^{99} \mathrm{Tc}$ found in the analysed soil samples. Further analyses will be carried out to confirm these results and 
determine the rate of ${ }^{99} \mathrm{Tc}$ release over the later period of the experiment when the $\mathrm{CO}_{2}$ production rate had increased.

\section{FURTHER EXPERIMENTS}

Research has shown that the mobility and solubility of ${ }^{99} \mathrm{Tc}$ in the soil is determined by its chemical form and that plant uptake depends not on the total concentration of ${ }^{99} \mathrm{Tc}$ in the soil but on the concentration of the soluble pertechnetate ion in the soil solution [5].

An experiment is currently running which aims to build on the findings of the initial experiment. This larger scale experiment will monitor the release of ${ }^{99} \mathrm{Tc}$ into soil solution over time. The experiment uses Fucus vesiculosus and sandy soil from the same locations as the initial experiment. Twenty large (25L) pots have been set up in 4 sets, each with 5 replicates:

Set I: $1 \mathrm{~kg}$ (wet wt) seaweed chopped into $4-6 \mathrm{~cm}$ pieces mixed evenly with $7 \mathrm{~kg}$ (field moist) soil,

Set 2: $1 \mathrm{~kg}$ seaweed (wet wt) cut into $20-25 \mathrm{~cm}$ pieces mixed evenly with $7 \mathrm{~kg}$ (field moist) soil

Set $3: 1 \mathrm{~kg}$ seaweed (wet wt) chopped into $4-6 \mathrm{~cm}$ pieces mixed evenly with $7 \mathrm{~kg}$ (field moist) soil, 4 spinach plants planted per pot 3 weeks after set-up.

Set 4: Controls, $7 \mathrm{~kg}$ (field moist) soil only.

All pots have in-situ Rhizon soil solution samplers and are kept at ambient temperature and $75 \%$ field capacity. The experiment began at the beginning of July 2001 and is still running. At weekly intervals $\mathrm{CO}_{2}$ production of the pots in sets 1,2 and 4 is measured and in the $24-36$ hours afterwards soil solution is extracted from all 20 pots. This soil solution will be analysed for soluble carbohydrate and amino acid content as indicators of decomposition rate and ${ }^{99} \mathrm{Tc}$ content. Chemical speciation of the ${ }^{99} \mathrm{Tc}$ in the soil solution will be determined using gelfiltration chromatography. The spinach plants will be harvested after 40 days and analysed for ${ }^{99} \mathrm{Tc}$ to show the uptake of ${ }^{99} \mathrm{Tc}$ from the soil solution. All soil solution and plant samples will be analysed for ${ }^{99} \mathrm{Tc}$ using the method devised by Wigley et al. [8].

Further experiments are planned over the next 12 months to investigate the release of ${ }^{99} \mathrm{Tc}$ from Fucus vesiculosus.

\section{References.}

[1] K.S. Leonard, D. McCubbin, J. Brown, R. Bonfield and T. Brooks, T. Mar. Pollut. Bull. 34(8), 628$636(1997)$

[2] J. Brown, A.K. Kolstad, B.Lind, A.L.Rudjord.and P. Strand, Stralevern Rapport 1998:3

[3] W.C. Camplin, S. Rollo and J.Hunt, Surveillance related assessments of sea-to-land transfer. in Proceedings of the Second RADREM-TESC Workshop, London, January 1999

[4] R.E.Wildung, T.R. Garland, and D.A.Cataldo, Health Phys. 32 314-317 (1977)

[5] L.R. Van Loon, Kinetic aspects of the soil-to-plant transfer of technetium. PhD thesis. Katholieke Univerisiteit te Leuven (1986)

[6] J.F.M.M.Lembrechts and G.M. Desmet, in Technetium in the Environment. edited by Desmet, G.M. and Myttenaere, C (Elselvier Applied Science, London-New York, 1986). 295-300

[7] G. Echevarria, P.C.Vong, E. Leclerc-Cessac and J.L.Morel, J. Environ. Qual. 26 947-956. (1997)

[8] F. Wigley, P.E.Warwick, I.W.Croudace, J. Carbom and A.L.Sanchez, Anal. Chim. Acta. 380 73-82 (1999).

[9] C.H. Dickinson, in Biology of Plant Litter Decomposition, edited by C.H. Dickinson and G,J.F. Pugh, Volume 2 (Academic Press, London and New York, 1974) 633-658 